International Journal of Applied Dental Sciences 2021; 7(1): 272-276

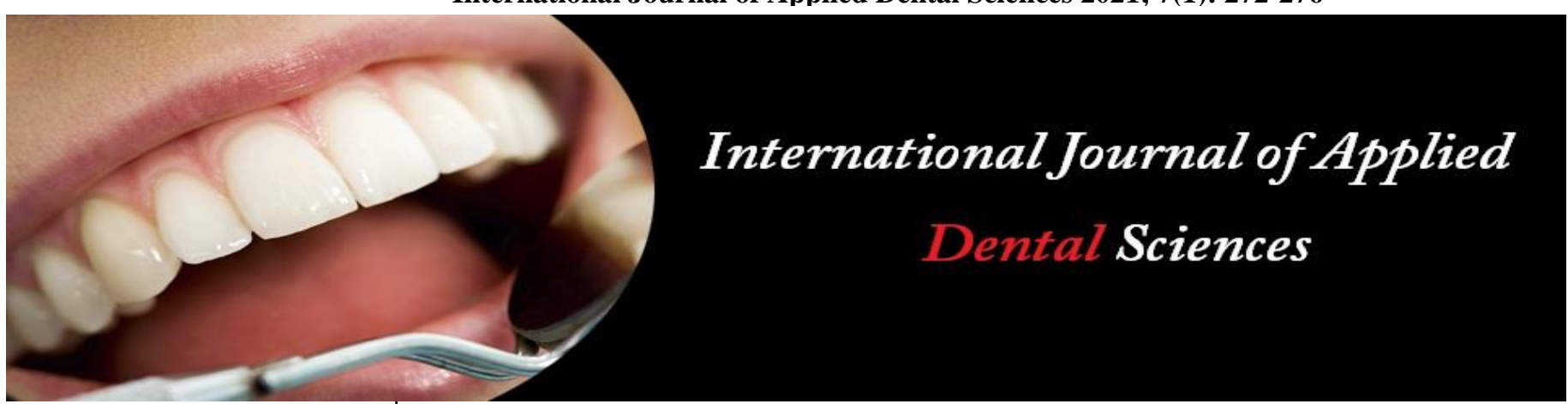

ISSN Print: 2394-7489

ISSN Online: 2394-7497

IJADS 2021; 7(1): 272-276

(C) 2021 IJADS

www.oraljournal.com

Received: 19-11-2020

Accepted: 21-12-2020

Houda El Ayachi

Resident in the Periodontology

Department, Dental

Consultation and Treatment

Center in Rabat, Faculty of

Dental Medicine of Rabat,

Mohammed V University,

Morocco

\section{Assimi Sihame}

Assistant Professor in the

Periodontology Department,

Dental Consultation and

Treatment Center in Rabat,

Faculty of Dental Medicine of

Rabat, Mohammed V

University, Morocco

\section{Amine Cherkaoui}

Professor of Higher Education in the Periodontology Department, Dental Consultation and

Treatment Center in Rabat,

Faculty of Dental Medicine of

Rabat, Mohammed V

University, Morocco
Corresponding Author:

Houda El Ayachi

Resident in the Periodontology

Department, Dental

Consultation and Treatment

Center in Rabat, Faculty of

Dental Medicine of Rabat,

Mohammed V University,

Morocco

\section{Periodontal management of changes in gingiva during pregnancy: A nonsurgical approach}

\author{
Houda El Ayachi, Assimi Sihame and Amine Cherkaoui
}

DOI: $\underline{\text { https://doi.org/10.22271/oral.2021.v7.i1d.1144 }}$

\begin{abstract}
Gingivitis is a major and frequent unwanted effect accompanying pregnancy. Sometimes, pregnancy gingivitis may show a tendency for localized enlargement, which is called "pregnancy granuloma". The local factors such as plaque and calculus are known to be responsible for gingival enlargement during pregnancy. The hormonal factors also play a role in aggravating the enlargement. The management of gingival enlargement includes nonsurgical approach, surgical approach, or both of them for severe cases. This case report illustrates a successful nonsurgical management of a 32-year-old female patient with gingivitis associated to localized gingival enlargement. The lesion was observed during pregnancy and persisted postpartum, a total regression of the gingival enlargement without any surgical procedure was observed. And it highlights therefore the key role of supportive periodontal therapy in maintaining good and stable outcomes over years of follow-up.
\end{abstract}

Keywords: pregnancy gingivitis, gingival enlargement, nonsurgical approach

\section{Introduction}

During pregnancy a variety of physiological and hormonal changes occur in all systems and parts of the woman's body. Some of the endocrine and immune changes induced by pregnancy increase the susceptibility to various infections, including those of the oral cavity [1]. Periodontal disease including gingivitis, periodontitis has been associated with pregnancy ${ }^{[2,3]}$. Gingivitis is the most prevalent oral manifestations associated with pregnancy. Pregnancy gingivitis, defined as gingival inflammation initiated by plaque and exacerbated by endogenous sex steroid hormones ${ }^{[4]}$. it is included in the American Association of Periodontology classification of periodontal diseases 2017 as a "plaque-induced gingivitis and modifying factors ${ }^{[5]}$. Depending on whether dental plaque biofilm-induced gingival inflammation occurs on an intact or reduced periodontium, or in a patient diagnosed with periodontitis, gingivitis can be further classified as: Gingivitis on an intact periodontium, Gingivitis on a reduced periodontium in a non-periodontitis patient (recession, crown lengthening) and gingival inflammation on a reduced periodontium in a successfully treated periodontitis patient ${ }^{[6]}$. Symptoms of gingivitis in pregnancy typically emerge more commonly in the 2nd and 3rd trimesters; and recover spontaneously to levels measured early in pregnancy after parturition period ${ }^{[7,8]}$. It is generally accepted that increased circulating levels of female sex-hormones play a central role in the etiology of pregnancy gingivitis and have been known to be associated with varying types of gingival enlargement. Hormonal changes can significantly potentiate the effects of local irritants on gingival connective tissue from mild inflammation to severe hyperplasia, pain and profuse bleeding ${ }^{[3]}$.

These alterations can predispose the pregnant woman to periodontal inflammation, where Pyogenic granuloma (PG) is a reactional lesion resulting from this inflammation, called as "pregnancy tumor" or "granuloma gravidarum." It is a nonspecific conditioned gingival enlargement in response to bacterial plaque and due to chronic local irritation and trauma ${ }^{[9]}$. The small lesions of PG usually regress spontaneously after delivery. Moreover, even after childbirth, there was no remission, the lesions were also surgically treated ${ }^{[10]}$.

Different treatment options can be suggested to manage gingival enlargement; they can be categorized as nonsurgical approach and surgical approach. The nonsurgical approach is aimed 
at reducing the inflammatory component in gingival tissue. The surgical approach eliminates the fibrotic component of the gingival tissue when it is severe and persists after the nonsurgical therapy.

In this case report, we describe and discuss through literature data, localised of postpartum gingival enlargement treatment in a young patient, who underwent a successful nonsurgical periodontal treatment and supportive periodontal therapy for over 3 years of follow-up.

\section{Observation}

A 32-year-old female patient was referred to the Department of Periodontology at Rabat Dental College and Hospital, with the chief complaint of localised gingival enlargement in relation to 43 and 44 since 1 year, pain in the gums, unsatisfactory esthetics and bleeding from the gums during brushing.

The medical history of the patient revealed that the patient was in good health with no history of any systemic disease and/or condition. She had no known drug allergy and was not taking any medication. The patient was pregnant at the time of initiation of swelling and the swelling came to the present size after the delivery of the baby. Prior to pregnancy, patient had follow-up appointments with her dentist for which she was diagnosed with generalised moderate periodontitis stage II grade B through a comprehensive examination.

Intraoral examination showed a very poor oral plaque control. Subgingival calculus and plaque were present. The plaque index by Silness and Loe (PI) ${ }^{[11]}$ was 1,75 and the gingival index (GI) ${ }^{[12]}$ was 2.75 . There was an inflamed, red, granular and smooth marginal and attached gingiva. Generalised gingivitis was present from mild inflammation to severe. On examination, there was a sessile, lobulated solitary gingival enlargement between 43 and 44. It was severely inflamed and bleeding on probing was present. On palpation, the growth was moderately firm in consistency and was non-tender. Obvious calculus was noted surrounding the lesion (figures 1 , 2).

On examination with a William's periodontal probe, periodontal pocket of approximately $4 \mathrm{~mm}$ on distal of 44 and $5 \mathrm{~mm}$ on mesial of 43 was elicited. The rest of the dentition had normal periodontal probing values with clinical attachment loss varied from 3 to $7 \mathrm{~mm}$. Based on the clinical findings and the patient's recent pregnancy, the lesion was provisionally diagnosed as granuloma gravidum.

Periapical radiograph revealed horizontal bone loss in relation to 43 and 44 regions (figure 4 ).

Accordingly to the new classification system of periodontal diseases and conditions from the American Academy of Periodontology and the European Federation of Periodontology 2018 [7], the diagnosis was "gingival overgrowth with underlying pregnancy gingivitis on a reduced periodontium in a successfully treated periodontitis patient".

The management strategy consisted of a nonsurgical periodontal therapy based, initially, on oral hygiene instruction. On the second-time round, a full-mouth scaling and root planning were performed a week later as well as polishing of all the rough dental surfaces.

Two months after the periodontal treatment (hygienic phase), the clinical evaluation showed a successful regression of the inflammation and improvement of periodontal parameters. We have noted a reduction of pockets' depth and plaque and gingival index scores which become, respectively, PI: 0.4 and GI: 0.7. Thus, a supportive therapy was established including the reinforcement of oral hygiene instruction and full-mouth scaling every 2 months. The whole treatment resulted in the total disappearance of gingival overgrowth without any surgical procedure.

In the present case report, we could not do any histopathological exploration because of the total regression of the gingival overgrowth after the nonsurgical periodontal therapy. So, we did not have any remaining gingival overgrowth tissue specimen for exploration. We could conclude that the more predominant etiology was probably dental biofilm, calculus and hormonal changes.

The last clinical evaluation after 3 years of regular follow-up shows the good stability of the results (figure 5-7).

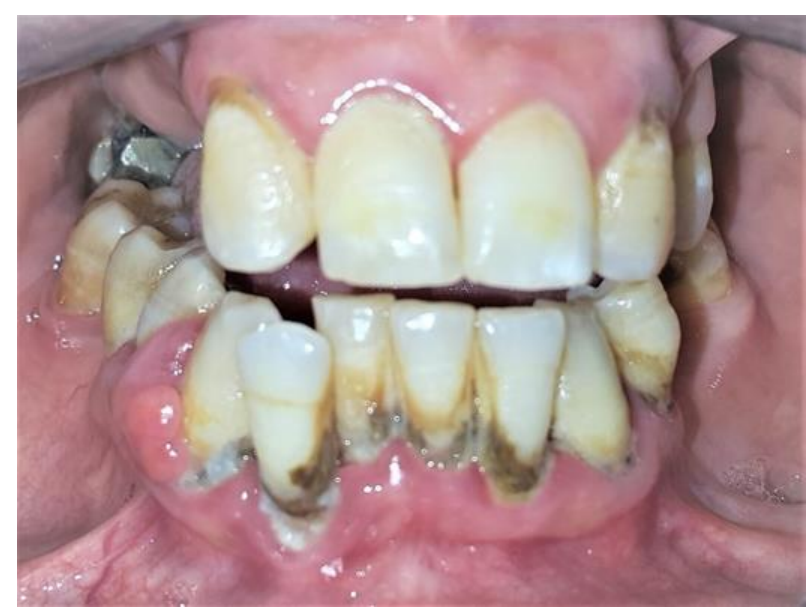

Fig 1: Baseline front view

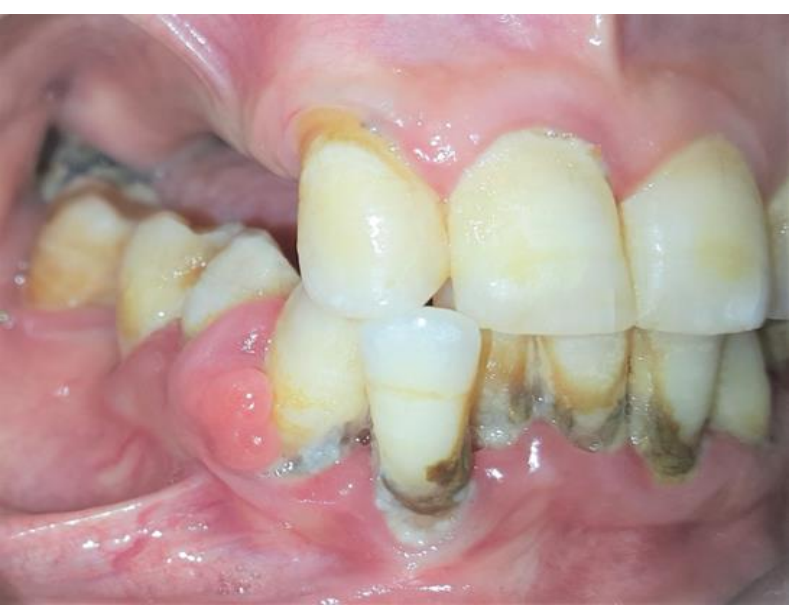

Fig 2: Baseline right side view

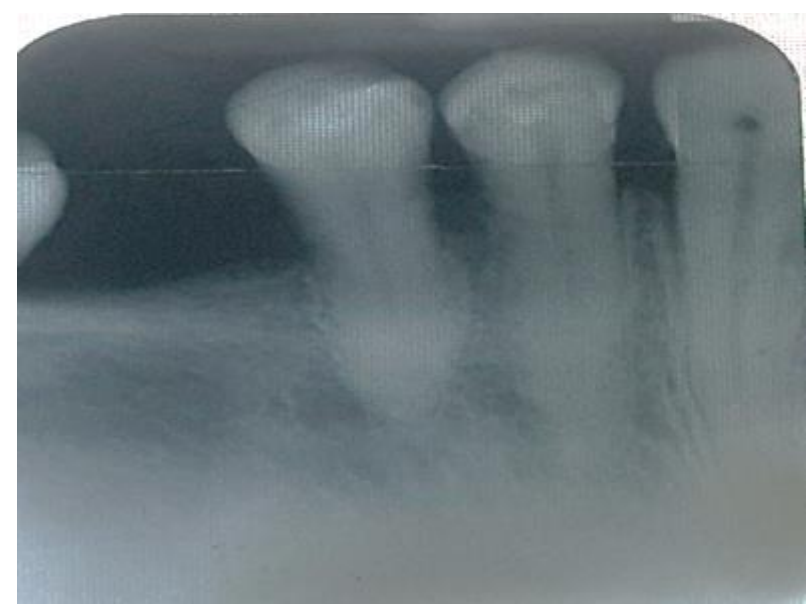

Fig 3: Periapical radiographs 


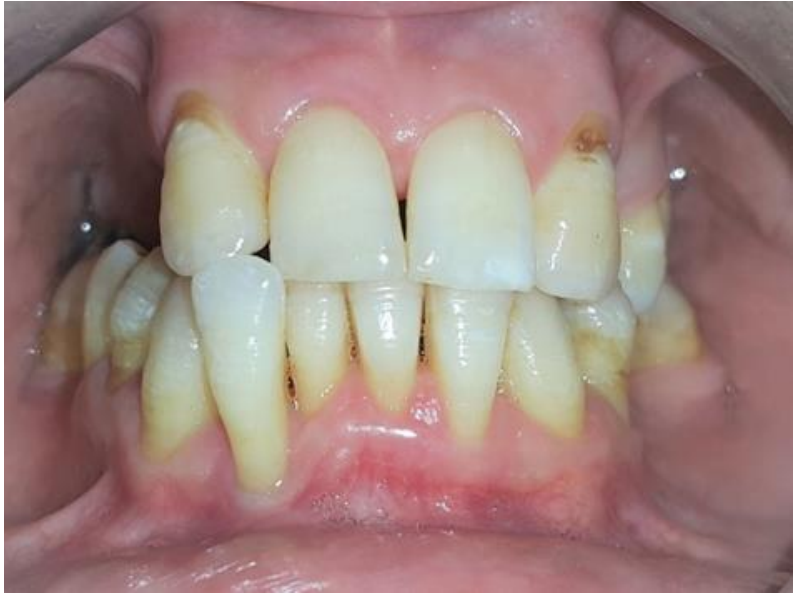

Fig 4: Final front view 3 years post treatment

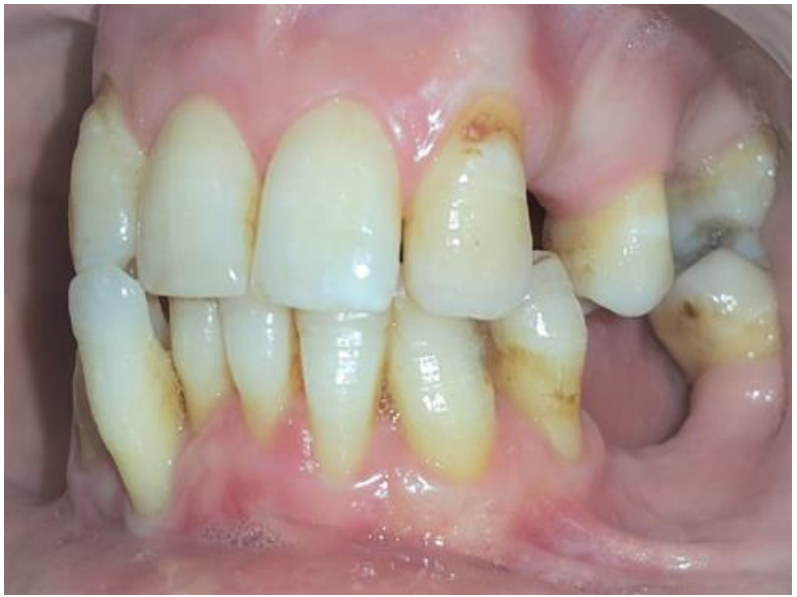

Fig 5: Final right side view 3 years post treatment

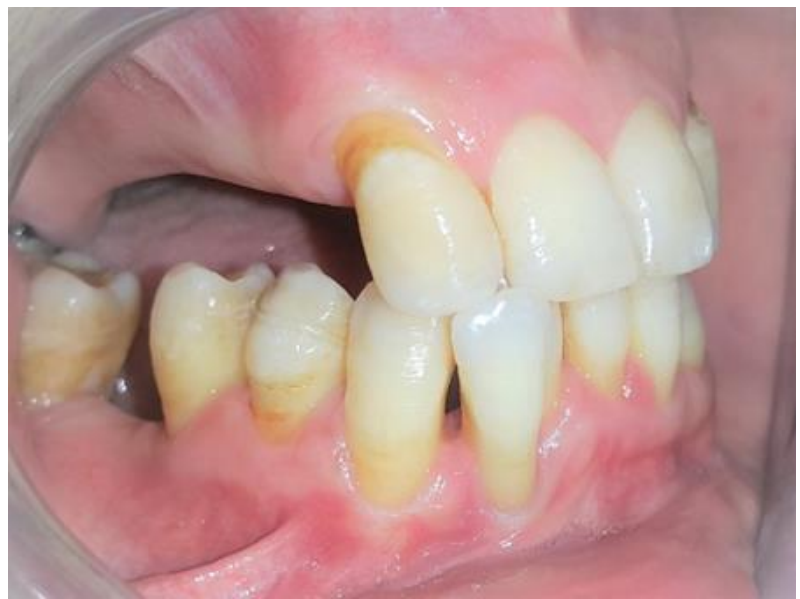

Fig 6: Final left side view 3 years post treatment

\section{Discussion}

Pregnancy is identified as a sensitive period of increased risk for periodontal disease, psychosocial symptoms and poor oral health ${ }^{[13]}$. The inflammatory changes in gingiva during pregnancy have been termed as pregnancy-associated gingivitis ${ }^{[7]}$. In addition to gingival changes, there may also be periodontal changes such as increased pocket depth, minimal loss of attachment, and increased tooth mobility ${ }^{[14]}$. Many studies suggested that pregnancy only has a reversible effect on the gingiva without inducing significant clinical periodontal attachment loss ${ }^{[7,10,15]}$. In contrary, Vogt et al. reported more cases of periodontal damage with greater clinical attachment loss in pregnant women in trimester III
[16].

Gingivitis is the most common oral manifestation with a prevalence ranged widely from 35 to $100 \%{ }^{[17]}$. Some crosssectional research showed that the percentage of pregnant women with gingivitis was $89 \%$ in Ghana, $86.2 \%$ in Thailand and $47 \%$ in Brazil ${ }^{[18,19]}$. In Nepal a recent study found approximately $40 \%$ of women to have gingivitis and $79 \%$ to have $\geq 1$ site with bleeding on probing ${ }^{[20]}$.

The severity of gingivitis increased in parallel with the increase in the gestational age. It may be explained by the fact that progesterone and estrogen increase with gestational age of pregnancy reaching their peak plasma levels in the thirdtrimester ${ }^{[21,22]}$. The gradual increase in severity of gingivitis toward the end of pregnancy has also been reported by many authors ${ }^{[3,15,23]}$. In contrary, few studies reported the greater gingival disease during trimester II of pregnancy ${ }^{[14,24,25]}$.

It is observed that the severity of gingivitis is reduced after postpartum ${ }^{[7,26]}$. but the gingiva does not necessarily return to a state of health ${ }^{[27]}$. Also, Cohen et al. observed a partial remission of periodontal disease at 3-month and 15-month in their two longitudinal studies ${ }^{[14,28]}$.

The underlying mechanisms by which the prevalence and severity of gingivitis are greater in pregnant women still unclear. It is supposed that gingival inflammation is initiated by periodontal pathogens and exacerbated by endogenous steroid hormones during gestation ${ }^{[29,30]}$.

During pregnancy increase in gingival inflammation even under good oral hygiene control and resolution following parturition made most of the investigators consider the alterations in the progesterone and estrogen levels during pregnancy to be the major etiologic factor ${ }^{[16,31]}$.

The increase in progesterone results in greater vascular permeability, gingival edema, crevicular fluid levels and prostaglandin production, which may lead to gingival inflammation. In addition, may affects the development of local inflammation, reducing regulation of interleukin- 6 production and rendering gingival tissues less resistant to inflammatory challenges caused by bacterial plaque ${ }^{[16]}$.

Pregnancy-associated gingivitis has been suggested that estrogen and progesterone can modulate the putative periodontal pathogens ${ }^{[16,32]}$.

Previous analyses of microbiological culture have demonstrated that the subgingival flora changes to a more anaerobic flora as pregnancy progresses. Prevotella intermedia is the microorganism that increases significantly during pregnancy ${ }^{[25]}$. Also in their recent study, on the basis of clinical and microbiologic findings, Emmatty and al. reported that the exaggerated gingival response during pregnancy may be associated with increase in the prevalence of Prevotella intermedia in the subgingival plaque ${ }^{[23]}$.

These inflammatory changes may lead to gingiva that appears edematous, hyperplastic and erythematous; the changes may be localized or generalized and are usually noted on the marginal gingiva and interdental papilla ${ }^{[33,34]}$.

Sometimes, pregnancy gingivitis may show a tendency for localised enlargement, which is called "pregnancy granuloma or granuloma gravidarum. It may also occur during the first and second trimesters of pregnancy in about $2 \%$ of women [35].

The gingival enlargement has been associated with a variety of local and systemic factors so differential diagnosis becomes an important aspect for complete treatment of the lesion.

Differential diagnosis of granuloma gravidarum includes peripheral giant cell granuloma, peripheral ossifying fibroma, 
fibroma, peripheral odontogenic fibroma, hemangioma, conventional granulation tissue, hyperplastic gingival inflammation, Kaposi's sarcoma, bacillary angiomatosis, angiosarcoma, non-Hodgkin's lymphoma and metastatic tumors ${ }^{[36]}$.

In all forms of enlargements, good oral hygiene is necessary to minimize the effects of systemic factors. As far as periodontal treatment is concerned, current treatment options include nonsurgical interventions alone or a combination of nonsurgical and surgical interventions. Nonsurgical approaches include an oral hygiene program, a scaling and root planning, and also the elimination of local irritant factors that enhance plaque accumulation (faulty restorations, broken teeth, or carious lesions).

Zhu and al. reported that initial periodontal therapy combined with oral hygiene maintenance is efficacious in treating gingival pregnancy granuloma with normal hormone levels, which can eliminate irritants and could potentially serve as an option to avoid surgery. In their study the patients received initial periodontal therapy, then supportive periodontal therapies at 3- to 6-month intervals. The patients underwent follow up for 6 months to 8 years after treatment. No recurrence of gingival pregnancy tumors was noted during subsequent follow-up. Considering the etiological factors and clinical characteristics, they assume that initial periodontal therapy could eliminate irritants and yield high clinical efficacy ${ }^{[37]}$.

When the gingival enlargement is severe or persists, despite good plaque control and initial periodontal therapy, surgical correction is advocated. It includes conventional scalpel techniques, cryotherapy, electrocautery, sclerotherapy and laser therapy ${ }^{[38,39]}$. Excisional surgery remains the most common therapy for pyogenic granuloma ${ }^{[40]}$. However, the surgical approach may produce unwanted mucogingival defects and severe gingival injury, especially when the pregnancy tumor is located in the anterior region ${ }^{[41]}$. Other treatment options include excision using lasers, cryosurgery or electrodesiccation would also result in large areas healing by secondary intention and limitations similar to excision ${ }^{[42]}$. Initial periodontal therapy yields mild oral trauma, which is especially suitable for patients who are reluctant or afraid of undergoing surgery. More importantly, it is an appropriate choice for those with a health condition too poor to receive surgery, such as lactating women ${ }^{[38]}$.

So, the regular supportive periodontal therapy is effective in resolving the inflammation and the gingival overgrowth and in eliminating the need for surgical treatment ${ }^{[37]}$. That was highlighted in this case report with more than 36 months of regular follow-up.

Partial or complete regression after parturition is one of the clinical features of pregnancy granuloma ${ }^{[43]}$. However, the underlying molecular mechanism remains unclear. It has been proposed that, in the absence of vascular endothelial growth factor (VEGF), angiopoietin-2 (Ang-2) causes blood vessels to regress. Therefore, we investigated the roles of Ang-2 and VEGF in the regression of pregnancy pyogenic granuloma ${ }^{[44]}$. Periodontal surgery is relatively contraindicated during pregnancy ${ }^{[45]}$. So a better understanding of the molecular mechanism may provide new strategies for improving nonsurgical therapy to control the disease.

\section{Conclusion}

Gingival changes are a serious side effect during pregnancy. The diagnosis is easy according to medical history and intraoral examination of the patient. Hormonal changes occurring during pregnancy have been known to be associated with generalised or localised gingival enlargement and the presence of local factors may accentuate the gingival response. The treatment options can be categorized as nonsurgical therapy alone or a combination of nonsurgical and surgical therapy. All these approaches have been attempted to either reduce or eliminate gingival enlargement and its pockets. Finally, it is extremely important to include oral hygiene practices and maintenance visits during the pregnancy period. There is a need to institute antenatal oral health care that will provide preventive measures to reduce the prevalence of gingival and periodontal disease.

\section{References}

1. Armitage GC. Bi-directional relationship between pregnancy and periodontal disease. Periodontol 2000 2013;61(1):160-176.

2. Wu M, Chen SW, Jiang SY. Relationship between gingival inflammation and pregnancy. Mediators of Inflammation 2015,623427p.

3. Gürsoy M, Pajukanta R, Sorsa T, Könönen E. Clinical changes in periodontium during pregnancy and postpartum. J Clin Periodontol 2008;35(7):576-583.

4. Mariotti A. Sex steroid hormones and cell dynamics in the periodontium. Crit Rev Oral Biol Med 1994;5(1):2753.

5. Murakami S, Mealey BL, Mariotti A, Chapple ILC. Dental plaque-induced gingival conditions. J Periodontol 2018;89(Suppl 1):S17-S27.

6. Chapple ILC, Mealey BL et al. Periodontal health and gingival diseases and conditions on an intact and a reduced periodontium: Consensus report of workgroup 1 of the 2017 World Workshop on the Classification of Periodontal and Peri-Implant Diseases and Conditions. J Periodontol 2018;89(Suppl 1):S74-S84.

7. Tilakaratne A, Soory M, Ranasinghe AW, Corea SM, Ekanayake SL, de Silva M. Periodontal disease status during pregnancy and 3 months post-partum, in a rural population of Sri-Lankan women. Journal of Clinical Periodontology 2000;27(10):787-792.

8. Daley TD, Nartey NO, Wysocki GP. Pregnancy tumor: An analysis. Oral Surg Oral Med Oral Pathol 1991;72(2):196-9.

9. Freitas TM, Miguel MC, Silveira EJ, Freitas RA, Galvão HC. Assessment of angiogenic markers in oral hemangiomas and pyogenic granulomas. Exp Mol Pathol 2005;79(1):79 85.

10. Laine MA. Effect of pregnancy on periodontal and dental health. Acta Odontologica Scandinavica 2002;60(5):257264.

11. Silness J, Loe H. Periodontal disease in pregnancy. II. Correlation between oral hygiene and periodontal condition. Acta Odontol Scand 1964;22:121-35.

12. Loe H, Silness J. Periodontal disease in pregnancy I. Prevalence and severity. Acta Odontol Scand 1963;21:533-51.

13. Vamos CA, Walsh ML, Thompson E, Daley EM, Detman L, DeBate R. Oral-systemic health during pregnancy: exploring prenatal and oral health providers' information, motivation and behavioral skills. Matern Child Health J 2015;19(6):1263-1275.

14. Cohen DW, Friedman L, Shapiro J, Kyle GC. A longitudinal investigation of the periodontal changes during pregnancy. J Periodontol 1969;40(10):563-70.

15. Taani DQ, Habashneh R, Hammad MM, Batieha A. The 
periodontal status of pregnant women and its relationship with socio-demographic and clinical variables. J Oral Rehabil 2003;30(4):440-5.

16. Vogt M, Sallum AW, Cecatti JG, Morais SS. Factors associated with the prevalence of periodontal disease in low-risk pregnant women. Reprod Health 2012;9:3.

17. Onigbinde OO, Sorunke ME, Braimoh MO, Adeniyi AO. Periodontal status and some variables among pregnant women in a Nigeria tertiary institution. Ann. Med. Health Sci. Res 2014;4(6):852-857.

18. Mealey BL, Moritz AJ. Hormonal influences: effects of diabetes mellitus and endogenous female sex steroid hormones on the periodontium. Periodontology 2000 2003;32:59-81.

19. Rakchanok N, Amporn D, oshida YY, Harun-Or-Rashid M, Sakamoto J. Dental caries and gingivitis among pregnant and non-pregnant women in Chiang Mai, Thailand. Nagoya Journal of Medical Science 2010;72(12):43-50.

20. Erchick DJ, Rai B, Agrawal NK et al. Oral hygiene, prevalence of gingivitis, and associated risk factors among pregnant women in Sarlahi District, Nepal. BMC Oral Health 2019;19(1):2.

21. Al-Rayyan E, Masarwa N, Barakat M, Momani M, Khudair R. Frequency of gingivitis in pregnancy: A comparative study between first and third trimesters of pregnancy. J R Med Serv 2013;20:19-24.

22. Ganesh A, Ingle NA, Chaly PZ, Reddy CA. Survey on dental knowledge and gingival health of pregnant women attending government maternity hospital, Chennai. J Oral Health Community Dent 2011;5:24-30.

23. Emmatty R, Mathew JJ, Kurnvilla J. Comparative evaluation of subgingival plaque microflora in pregnant and non-pregnant women: A clinical and microbiological study. J Indian Soc Periodontol 2013;17(1):47-51.

24. Steinberg BJ. Women's oral health issues. J Dent Educ 1999;63(3):271-5.

25. Kornman KS, Loesche WJ. The subgingival microbial flora during pregnancy. J Periodontal Res 1980;15(2):111-22.

26. Hugoson A. Gingival inflammation and female sex hormones. A clinical investigation of pregnant women and experimental studies in dogs. J Periodontal Res Suppl 1970;5:1-8.

27. Hilming F. Gingivitis gravidarum; studies on clinic and on etiology with special reference to the influence of Vitamin C. Oral Surg Oral Med Oral Pathol 1952;5(7):734-51.

28. Cohen DW, Shapiro J, Friedman L, Kyle GC, Franklin S. A longitudinal investigation of the periodontal changes during pregnancy and fifteen months post-partum. II. J Periodontol 1971;42(10):653-7.

29. Bakhtian H, Esmaeili S, Tabatabayi SF, Ellini MR, Nekoofar MH, Dummer PM. Second-generation platelet concentrate (Platelet-rich Fibrin) as a scaffold in regenerative endodontics: a case series. J. Endod 2017;43(3):401-408.

30. Galler KM, Brandl FP, Kirchhof S, Widbiller M, Eidt A, Buchalla $\mathrm{W}$ et al. Suitability of different natural and synthetic biomaterials for dental pulp tissue engineering. Tissue Eng Part A 2018;24(3-4):234-244.

31. Figuero E, Carrillo-De-Albornoz A, Herrera D, Bascones-Mart'inez A. Gingival changes during pregnancy: I. Influence of hormonal variations on clinical and immunological parameters. Journal of Clinical
Periodontology 2010;37(3):220-229.

32. Paropkari AD, Leblebicioglu B, Christian LM, Kumar PS. Smoking, pregnancy and the subgingival microbiome. Sci. Rep 2016;6:30388.

33. Offenbacher S, Lin D, Strauss R, McKaig R, Irving J, Barros SP et al. Effects of periodontal therapy during pregnancy on periodontal status, biologic parameters, and pregnancy outcomes: A pilot study. J Periodontol 2006;77(12):2011-24.

34. Clothier B, Stringer M, Jeffcoat MK. Periodontal disease and pregnancy outcomes: Exposure, risk and intervention. Best Pract Res Clin Obstet Gynaecol 2007;21(3):451-66.

35. Kikelomo Adesina T, Moninuola Ernest A, Abiola Tobin O, Salamat Isiaka-Lawal A, Moshood Adeyemi F, Adebunmi Olarinoye $\mathrm{O}$ et al. Oral health status of pregnant women in Ilorin, Nigeria. Journal of Obstetrics and Gynaecology 2018;38(8):1093-1098.

36. Sato H, Takeda Y, Satoh M. Expression of the endothelial receptor tyrosine kinase tie2 in lobular capillary hemangioma of the oral mucosa: An immunohistochemical study. J Oral Pathol Med 2002;31:432-8.

37. Zhu YQ, Wang YQ, Tang YC, Li CZ. Initial periodontal therapy for the treatment of gingival pregnancy tumor. Genet Mol Res 2016,15(2).

38. Tsai KY, Wang WH, Chang GH, Tsai YH. Treatment of pregnancy-associated oral pyogenic granuloma with lifethreatening haemorrhage by transarterial embolisation. J. Laryngol. Otol 2015;129(6):607-610.

39. Wang SQ, Goldberg LH. Treatment of recurrent pyogenic granuloma with excision and frozen section for margin control. Dermatol. Surg 2008;34(8):1115-1116.

40. Esmeili T, Lozada-Nur F, Epstein J. Common benign oral soft tissue masses. Dent. Clin. North Am 2005;49(1):223240, $\mathrm{x}$.

41. Joda T. Esthetic management of mucogingival defects after total excision in a case of pyogenic granuloma. Eur. J. Esthet. Dent 2012;7(2):110-119.

42. Tiwari S, Neelakanti A, Sathyanarayana S. An innovative and less invasive management of recurrent pyogenic granuloma in the esthetic zone: A case report with 18month follow-up. J Indian Soc Periodontol 2017;21(3):241-244.

43. Seymour RA. The sex hormones. In: Seymour RA, Heasman PA, (eds). Drugs, diseases, and the periodontium. Oxford University Press: New York 1992,135-138p.

44. Yuan K, Lin MT. The roles of vascular endothelial growth factor and angiopoietin-2 in the regression of pregnancy pyogenic granuloma. Oral Dis 2004;10(3):179-85.

45. Little JW. Pregnancy and breast-feeding. In: Little JW, Falace DA, eds. Dental management of the medically compromised patient, 3rd edn. The CV Mosby Company: St Louis 1988,325-331p. 